\title{
Influence of the Treatment Used in Inflammatory Bowel Disease on the Protease Activities
}

This article was published in the following Dove Press journal:

International Journal of General Medicine

\author{
Ewa Dudzińska' \\ Aneta Strachecka (iD ${ }^{2}$ \\ Paulina Gil-Kulik (iD) ${ }^{3}$ \\ Janusz Kocki ${ }^{3}$ \\ Jacek Bogucki ${ }^{4}$ \\ Natalya Shemedyuk ${ }^{5}$ \\ Magdalena Gryzinska (D) ${ }^{2}$ \\ 'Chair of Public Health, Medical \\ University of Lublin, Lublin 20-093, \\ Poland; ${ }^{2}$ Subdepartment of General and \\ Molecular Genetics, Institute of Biological \\ Basis of Animal Production, University of \\ Life Sciences in Lublin, Lublin 20-950, \\ Poland; ${ }^{3}$ Chair of Medical Genetics, \\ Department of Clinical Genetics, Medical \\ University of Lublin, Lublin 20-080, \\ Poland; ${ }^{4}$ Department of Organic \\ Chemistry, Faculty of Pharmacy, Medical \\ University, Lublin 20-093, Poland; \\ ${ }^{5}$ Department Biotechnology and \\ Radiology, Stepan Gzhytskyi National \\ University of Veterinary Medicine and \\ Biotechnologies, Lviv 79010, Ukraine
}

Correspondence: Ewa Dudzińska Email ewadudzinska@umlub.pl
Introduction: There is growing evidence that intestinal proteases have a role in the pathogenesis of gastrointestinal inflammatory diseases. Inflammatory bowel disease (IBD), which includes Crohn's disease (CD) and ulcerative colitis (UC), has an additional source of proteases represented by infiltrated and activated inflammatory cells. The aim of our study was to determine proteolytic system activity in patients with CD and UC. We limited the number of proteases tested by determining proteases active in acidic, neutral and alkaline $\mathrm{pH}$. Materials and Methods: The study included 40 patients with IBD - 20 CD patients and 20 UC patients. The control group consisted of 20 healthy subjects. Among the $20 \mathrm{CD}$ patients, 17 were treated with aminosalicylates, 14 with azathioprine, and 4 with corticosteroids, while 8 patients were undergoing biological treatment. Among the 20 UC patients, 19 were treated with aminosalicylates, 8 with azathioprine, and 3 with corticosteroids. The total protein concentration was assayed by the Lowry method. The optimal $\mathrm{pH}$ was assayed in $\mathrm{pH}$ from 2.2 to 12.8 , separated by 0.2 intervals. Proteolytic activities were determined against different substrates (gelatine, haemoglobin, ovalbumin, albumin, cytochrome $\mathrm{C}$, and casein), and haemoglobin was the optimal substrate. Protease activities were determined according to Anson method. Determination of the activities of natural inhibitors of acidic, neutral and alkaline proteases is based on the Lee and Lin method.

Results: Decreases were observed in the activities of acid proteases $(\mathrm{pH} 5)$, alkaline proteases $(\mathrm{pH} 7)$, and neutral proteases $(\mathrm{pH} 7.6$ and 8.6) in the groups of $\mathrm{CD}$ patients in remission in comparison with the active phase. In the group of patients with biologically treated $\mathrm{CD}$ patients, acid protease activity ( $\mathrm{pH}$ 5.0) was lower than in $\mathrm{CD}$ patients not receiving biological treatment. Activities of neutral $(\mathrm{pH} 7.0)$ and alkaline $(\mathrm{pH} 7.6$ and 8.6) proteases in the plasma of patients with UC in remission were lower in comparison to the active phase. Activities of acid ( $\mathrm{pH} \mathrm{5.0)}$ ) and alkaline (8.6) protease inhibitors were higher in CD patients in the active phase in comparison to remission. In UC patients with exacerbation of the disease, the activity of alkaline ( $\mathrm{pH} 8.6$ ) protease inhibitors was increased compared to remission.

Conclusion: 1 . Our research may suggest that the immunomodulatory treatment used in IBD, aimed at reducing the level of leukocytes and reduction of inflammation, may contribute to a reduction in protease activity. 2 . The decrease of protease activities in patients with $\mathrm{CD}$ and $\mathrm{UC}$ in remission may be a marker suggesting the patients' response to the treatment.

Keywords: ulcerative colitis, Crohn's disease, proteases

\section{Introduction}

Inflammatory bowel disease (IBD), which includes mainly ulcerative colitis (UC) and Crohn's disease (CD), is a chronic and recurrent inflammatory condition of the 
gastrointestinal tract. ${ }^{1,2}$ Protease genes constitute about $2 \%$ of the mammalian genome, and their gene products are enzymes considered essential for processes such as development, coagulation, immunity, inflammation and cell death. ${ }^{3}$

The four categories of proteinases, cysteine, serine, aspartic, and metalloproteinases, are named and classified according to their essential catalytic component, usually an amino acid, in their active site. ${ }^{4}$

Proteases are important mediators in gastrointestinal physiology, produced and released by the pancreas to be activated in the intestinal lumen for digestive purposes. Proteolytic activity is also found in mucosal tissues in healthy conditions, where it plays a role in mucus consistency and mucosal antigen processing. ${ }^{5}$

Bacteria, helminths and yeasts potentially present in the intestinal lumen also produce and release proteases. Mast cells release various forms of proteases: tryptase, chymase, cathepsin G and granzyme B. Resident macrophages also produce and release various forms of proteases: matrix metalloproteinases (MMPs), caspase, and cathepsins D and L. In the inflamed gut, inflammatory cells are another major source of proteases, which they use to degrade extracellular tissues and intracellular particles, increasing their phagocytic properties. For example, neutrophils release massive amounts of elastase, proteinase-3 and cathepsin G5. Additionally, all resident cells of the gastrointestinal tract (GI) tract express intracellular proteases, ie, caspases, which have fundamental roles in cell apoptosis, and proteolytic enzymes - autophagins, responsible for autophagy processes. ${ }^{4}$

Proteases are subject to strict regulation. Most proteases are synthesized as inactive zymogens that become activated through a number of mechanisms, including cleavage by upstream proteases, dimerization or changes in $\mathrm{pH}$. Proteases are also subject to inactivation by endogenous inhibitors, and thus the balance of active and inactive proteases is tightly controlled. ${ }^{6}$

In intestinal pathophysiological contexts such as inflammatory bowel disease, proteolytic homeostasis can be disrupted in tissues. ${ }^{5}$ There is growing evidence that intestinal proteases have a role in the pathogenesis of gastrointestinal inflammatory disease. ${ }^{3}$

IBD, which include $\mathrm{CD}$ and $\mathrm{UC}$, have an additional source of proteases represented by infiltrated and activated inflammatory cells. Some studies have shown that the expression of a very large number of proteases is upregulated in IBD. ${ }^{4}$ The expression and activity of certain
MMPs are increased during acute inflammation, but an imbalance between MMPs and their natural tissue inhibitors (TIMPs) has also been reported for IBD. ${ }^{7}$ Protein or mRNA expression of proteases from infiltrated immune cells (neutrophil elastase, tryptase, proteinase-3, cathepsin $\mathrm{G}$, chymase or granzymes) has also been shown to increase in inflamed tissues from patients with IBD. Inappropriate induction of cell death through apoptosis or autophagy is also associated with IBD, and proteases involved in such processes (caspases and autophagins) are upregulated in IBD, particularly UC. ${ }^{4}$

Given the large number of proteases that have been identified and their diverse functions in the development of IBD, it is quite difficult to specify which proteases are responsible for the manifestation of the pathological condition. ${ }^{4}$ However, in most previous studies assessed intestinal/luminal proteolytic activity and not systemic activity. Whereas IBD is frequently associated with the development of extraintestinal manifestations, the disease should be regarded as a systemic disorder not limited to the gastrointestinal tract. ${ }^{2}$ Moreover, the importance of plasma activity of proteases to IBD is unknown, and acquisition of blood samples in contrast to biopsy specimens is simple, therefore the aim of our study was to determine proteolytic system activity in the plasma of patients with $\mathrm{CD}$ and UC. We limited the number of proteases tested by determining proteases active in acidic, neutral and alkaline $\mathrm{pH}$.

\section{Materials and Methods}

The study included 40 IBD patients diagnosed in the Gastroenterology Ward and Gastroenterology Clinic of the Cardinal Stefan Wyszyński Regional Specialist Hospital in Lublin. The control group consisted of 20 healthy subjects (9 men and 11 women, 19-62 years of age). The IBD group consisted of $20 \mathrm{CD}$ patients (11 men and 9 women, aged 19-52), and 20 UC patients (12 men and 8 women, aged 27-46).

Among the $20 \mathrm{CD}$ patients, 17 were treated with aminosalicylates, 14 with azathioprine, and 4 with corticosteroids, while 8 patients were undergoing biological treatment (6 patients with Humira and 2 patients with Inflectra). The duration of the disease ranged from 0.5 to 16 years. There were 12 patients currently suffering exacerbation of the disease.

Among the 20 UC patients, 19 were treated with aminosalicylates, 8 with azathioprine, and 3 with corticosteroids. The duration of the disease ranged from 0.5 to 11 
years. There were 11 patients currently experiencing exacerbation. Disease activity score (UC: partial Mayo score; CD: Crohn's disease activity index/CDAI/) was recorded for each patient.

The material for the study consisted of plasma isolated from peripheral blood collected from the 40 IBD patients and the 20 healthy individuals.

The total protein concentration was assayed by the Lowry method, as modified by Schacterle and Pollack as follows: $5 \mu \mathrm{L}$ of copper reagent was added to $5 \mu \mathrm{L}$ solution/plasma samples for a ten-minute incubation at $25^{\circ}$ C. Subsequently, $20 \mu \mathrm{L}$ of Folin reagent was added (1:17) for a five-minute incubation at $55^{\circ} \mathrm{C}$. The resultant samples were analysed spectrophotometrically (Synergy HTX) to measure the absorbance at $650 \mathrm{~nm}$.

The optimal $\mathrm{pH}$ for activity of the enzymes was assayed in acidic, neutral, and alkaline buffer environments. We prepared buffers of defined $\mathrm{pH}$, from 2.2 to 12.8, separated by 0.2 intervals, as described by Łoś and Strachecka. ${ }^{9}$ Three micrograms of lyophilized hemoglobin should be added to $10 \mathrm{~mL}$ of each buffer. Five microlitres of each solution/plasma sample were incubated with $10 \mu \mathrm{L}$ of $1 \%(\mathrm{p} / \mathrm{v})$ haemoglobin in an appropriate buffer for 120 $\min$ at $37^{\circ} \mathrm{C}$. The reactions were ended by adding $40 \mu \mathrm{L}$ of cold 5\% trichloroacetic acid (TCA). The supernatant was analysed spectrophotometrically (Synergy HTX) to measure the absorbance at $280 \mathrm{~nm}$. The optimal $\mathrm{pH}$ values have been selected in which the enzymes revealed the highest proteolytic activity. Subsequent analyses are performed at these $\mathrm{pH}$ values.

Then proteolytic activity against substrates (gelatine, haemoglobin, ovalbumin, albumin, cytochrome $\mathrm{C}$, and casein) was tested by the Anson ${ }^{10}$ method as modified by Grzywnowicz et al, ${ }^{11}$ and Strachecka et al. ${ }^{12,13} 5 \mu \mathrm{L}$ of each solution/plasma sample were incubated with $10 \mu \mathrm{L}$ of each of the six substrates $(1 \%, \mathrm{p} / \mathrm{v})$ in an appropriate buffer for $120 \mathrm{~min}$ at $37^{\circ} \mathrm{C}$. The reactions were ended by adding $40 \mu \mathrm{L}$ of cold $5 \%$ trichloroacetic acid (TCA). The supernatant was analysed spectrophotometrically (Synergy HTX) to measure the absorbance at $280 \mathrm{~nm}$. The results indicated that haemoglobin was the optimal substrate for further analyses.

Activity of acid, neutral and alkaline proteases in their optimal $\mathrm{pH}$ were determined according to the method described by Anson, ${ }^{10}$ as modified by Strachecka et al. ${ }^{13}$ Five microlitres of each solution/plasma sample were incubated with $10 \mu \mathrm{L}$ of $1 \%(\mathrm{p} / \mathrm{v})$ haemoglobin in an appropriate buffer for $90 \mathrm{~min}$ at $37^{\circ} \mathrm{C}$. The reactions were ended by adding $40 \mu \mathrm{L}$ of cold $5 \%$ trichloroacetic acid (TCA); the undigested proteins were precipitated and centrifuged for $1 \mathrm{~min}$ at $12,000 \mathrm{rpm}$. The supernatant was spectrophotometrically analysed to measure the absorbance at $280 \mathrm{~nm}$. One unit of enzyme activity was defined as the amount of enzymes producing a 0.001 increase in absorbance per minute; according to Anson. ${ }^{10}$

Following the addition of diagnostic inhibitors, ie, pepstatin A, PMSF, iodoacetamide, and o-phenanthroline, proteolytic activity was determined according to Lee and Lin. ${ }^{14}$ Five microlitres of diagnostic inhibitors $(2 \mathrm{mM})$ were preincubated with $5 \mu \mathrm{L}$ of a given solution/plasma sample for $30 \mathrm{~min}$ at $37^{\circ} \mathrm{C}$. After this time, $25 \mu \mathrm{L}$ of $1 \%$ haemoglobin in an appropriate buffer was added and the incubation continued for $90 \mathrm{~min}$. The reactions were ended by adding $60 \mu \mathrm{L}$ of trichloroacetic acid (TCA) and the supernatants were measured as described above. Proteolytic activities after the addition of the diagnostic inhibitors were calculated according to the Lee $\&$ Lin method. ${ }^{14}$

Natural inhibitors of acid, neutral and alkaline proteases were determined according to Lee and Lin. ${ }^{14}$ The detailed protocols are described by Łoś and Strachecka. ${ }^{9}$ Pepsin was used as a marker for acidic, whereas trypsin for neutral and alkaline proteases. Five microlitres of pepsin or trypsin $(1 \mathrm{mg} / \mathrm{mL})$ were preincubated with 5 $\mu \mathrm{L}$ of a given solution/hemolymph sample for $30 \mathrm{~min}$ at $37^{\circ} \mathrm{C}$. After this time, $25 \mu \mathrm{L}$ of $1 \%$ haemoglobin in an appropriate buffer were added and the incubation was continued for $60 \mathrm{~min}$. The reactions were terminated by adding $60 \mu \mathrm{L}$ of trichloroacetic acid (TCA), centrifuged for $1 \mathrm{~min}$ at 12,000 rpm and the supernatants were spectrophotometrically analysed to measure the absorbance at 280 $\mathrm{nm}$. Inhibitor activities were calculated according to Lee \& Lin. $^{14}$

The data were analysed using the Statistica 13.3 statistics package. The significance level was set at $5 \%(\mathrm{p} \leq$ 0.05). The Mann-Whitney U-test, Kruskal-Wallis test $\mathrm{H}$ and $\mathrm{r}$-Spearman correlation were carried out.

\section{Results}

Protein concentrations in the plasma of patients with CD were significantly increased in comparison to the control group of healthy subjects and the UC patients (Figure 1).

Acidic proteases exhibited optimal activities at $\mathrm{pH} 5$, neutral proteases were active at $\mathrm{pH} 7$, and alkaline proteases were active at $\mathrm{pH} 7.6$ and 8.6 (Figure 2). Activities of acidic proteases ( $\mathrm{pH}$ 5.0) were decreased in CD patients in comparison to the healthy group. Alkaline proteases 


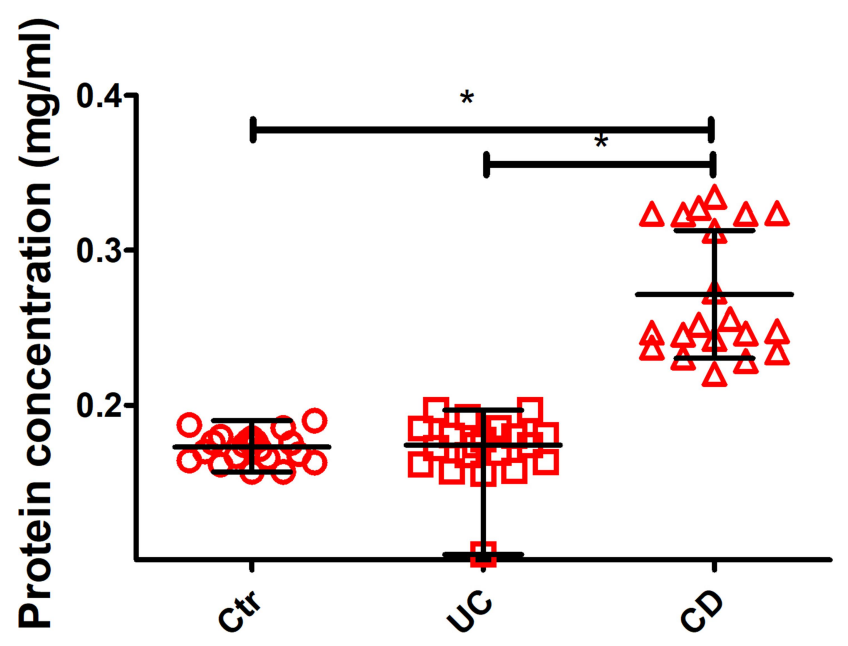

Figure I Protein concentration in the plasma of patients with Crohn's disease and ulcerative colitis (Median and range). The differences are statistically significant for comparisons between groups (control $N=20, C D N=20$ and $U C N=20$ ) at $* P \leq$ 0.05 .

( $\mathrm{pH}$ 8.6) were decreased in the plasma of $\mathrm{CD}$ and $\mathrm{UC}$ patients in comparison to the control group. Neutral $(\mathrm{pH} 7)$ and alkaline $(\mathrm{pH}$ 7.6) proteases in $\mathrm{CD}$ patients were decreased in comparison to the control group and UC (Figure 2). Decrease in acidic protease ( $\mathrm{pH} 5)$ and alkaline protease ( $\mathrm{pH} 8.6$ ) activities were observed in the groups of $\mathrm{CD}$ patients in remission in comparison with the active phase (Figure 4). In the group of patients with Crohn's disease treated biologically, acid protease activities $(\mathrm{pH}$ 5.0) were lower than in patients with Crohn's disease without biological treatment (Figure 6). Activities of alkaline $(\mathrm{pH} 7.6$ and 8.6) proteases in the plasma of patients with ulcerative colitis in remission were decreased in comparison to the active phase (Figure 7).

The protease inhibitors were active only at $\mathrm{pH} 5$ and 8.6 (Figures. 3,5 and 8). The activity of acidic (pH 5.0) and alkaline (8.6) protease inhibitors in the plasma of patients with Crohn's disease and ulcerative colitis showed a statistically significant decrease in comparison to the healthy group. The lowest inhibitory activity was observed in the group of patients with $\mathrm{CD}$ (Figure 3). Activities of acidic A (pH 5.0) and alkaline $B(8.6)$ protease inhibitors in patients with the active phase of $\mathrm{CD}$ are increased in comparison to patients in remission
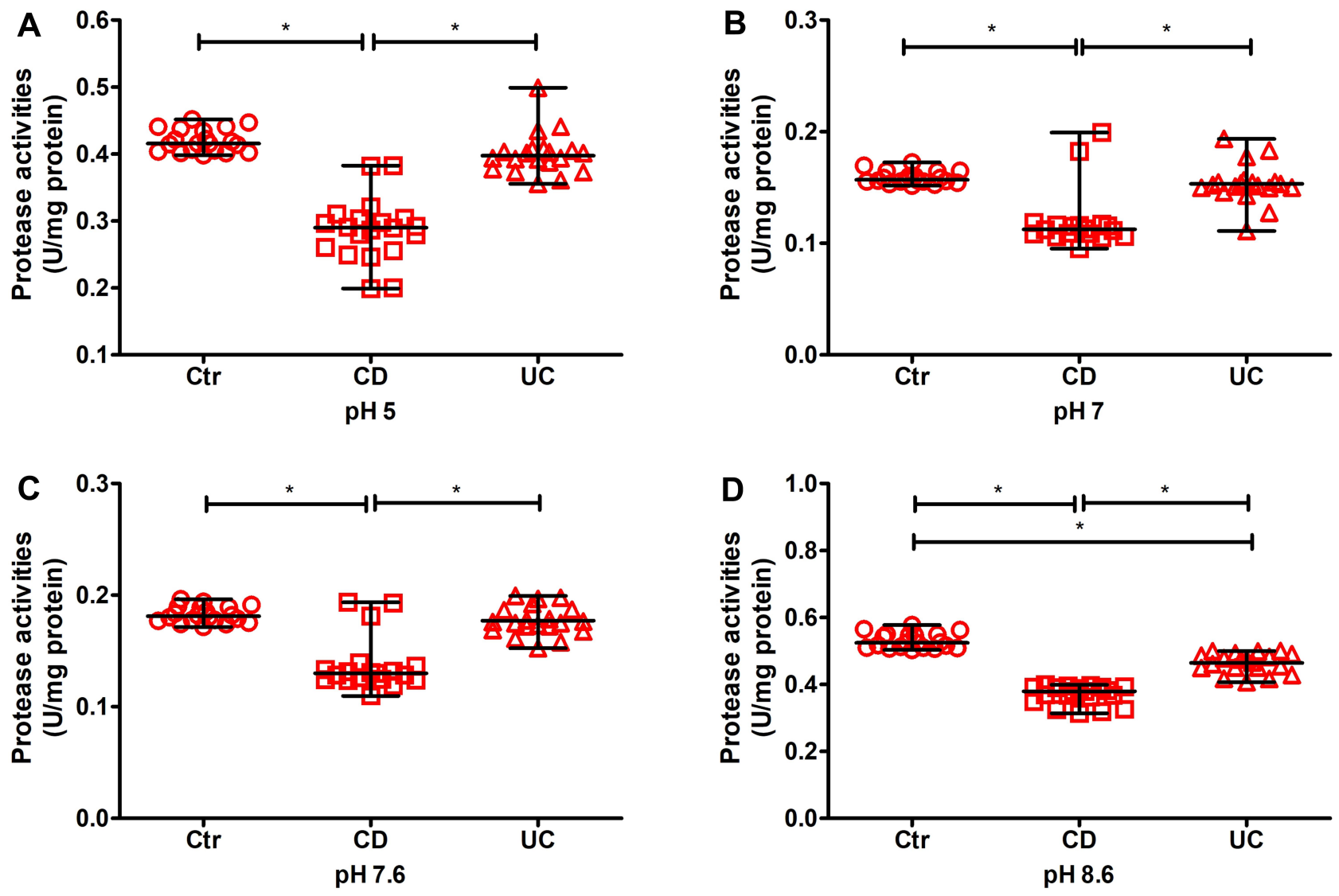

Figure 2 Activity of acidic (A) ( $\mathrm{pH} 5.0 ; \mathrm{N}$ for all groups=20), neutral $(\mathbf{B})(\mathrm{pH} 7.0 ; \mathrm{Ctr} \mathrm{N}=20, \mathrm{CD} \mathrm{N}=18, \mathrm{UC} \mathrm{N}=19)$ and alkaline (C and $\mathbf{D})$ (pH 7.6; $\mathrm{Ctr}$ and $\cup C \mathrm{~N}=20, \mathrm{CD}$ $\mathrm{N}=19$ and 8.6; $\mathrm{N}$ for all groups $=20$ ) proteases in the plasma of patients with Crohn's disease $(C D)$ and ulcerative colitis (UC) (Median and range). The differences are statistically significant for comparisons between groups (control, CD and UC) at $* \mathrm{P} \leq 0.05$. 

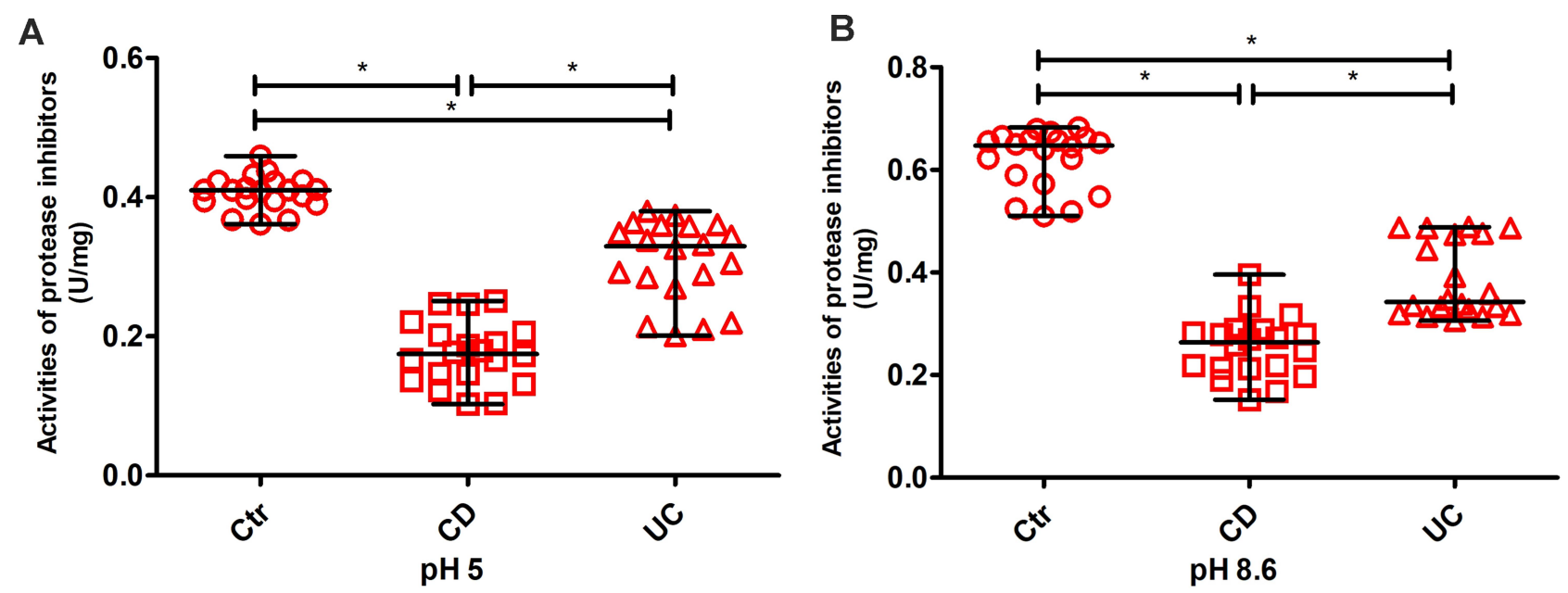

Figure 3 Activity of acidic (A) ( $\mathrm{pH} 5.0)$ and alkaline (B) (8.6) protease inhibitors in the plasma of patients with Crohn's disease (CD; N=20) and ulcerative colitis (UC; $\mathrm{N}=20)$ and $\mathrm{Ctr}(\mathrm{N}=20)$ (Median and range). The differences are statistically significant for *P $\leq 0.05$.
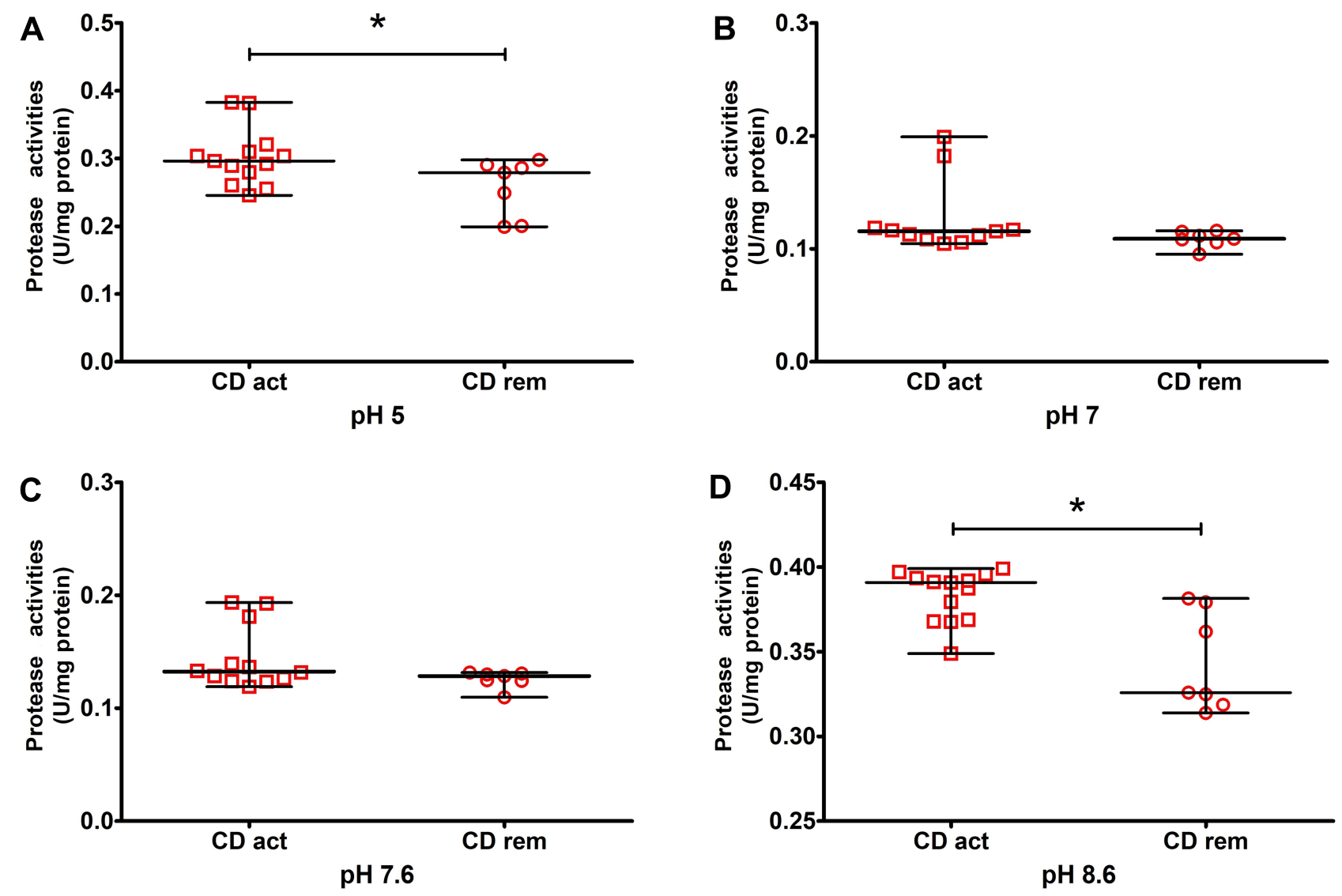

Figure 4 Activities of acidic $(\mathbf{A})(\mathrm{pH} 5.0 ; \mathrm{CD}$ act $\mathrm{N}=13, \mathrm{CD}$ rem $\mathrm{N}=7$ ), neutral $(\mathbf{B})(\mathrm{pH} 7.0 ; \mathrm{CD}$ act $\mathrm{N}=\mathrm{II}, \mathrm{CD}$ rem $\mathrm{N}=7)$ and alkaline $(\mathbf{C}$ and $\mathbf{D})$ ( $\mathrm{pH} 7.6$; $C D$ act $\mathrm{N}=12, \mathrm{Cd}$ rem $\mathrm{N}=7$ and 8.6; $C D$ act $N=13, C D$ rem $N=7$ ) proteases in the plasma of patients with Crohn's disease - active (act) and in remission (rem) (Median and range). The differences are statistically significant for comparisons between groups (act vs rem) at $* \mathrm{P} \leq 0.05$.

(Figure 5). The plasma activities of alkaline ( $\mathrm{pH} \mathrm{8.6)} \mathrm{protease}$ inhibitors were increased in patients with ulcerative colitis in the active phase compared to the group of patients in remission (Figure 8).
Asparagine (aspartic protease, MEROPS A9G.001), serine (serine endopeptidases) and thiol (cysteine proteases) proteases as well as metalloproteases (MMP) (activity after addition of pepstatin A, phenylmethylsulfone fluoride - PMSF, 

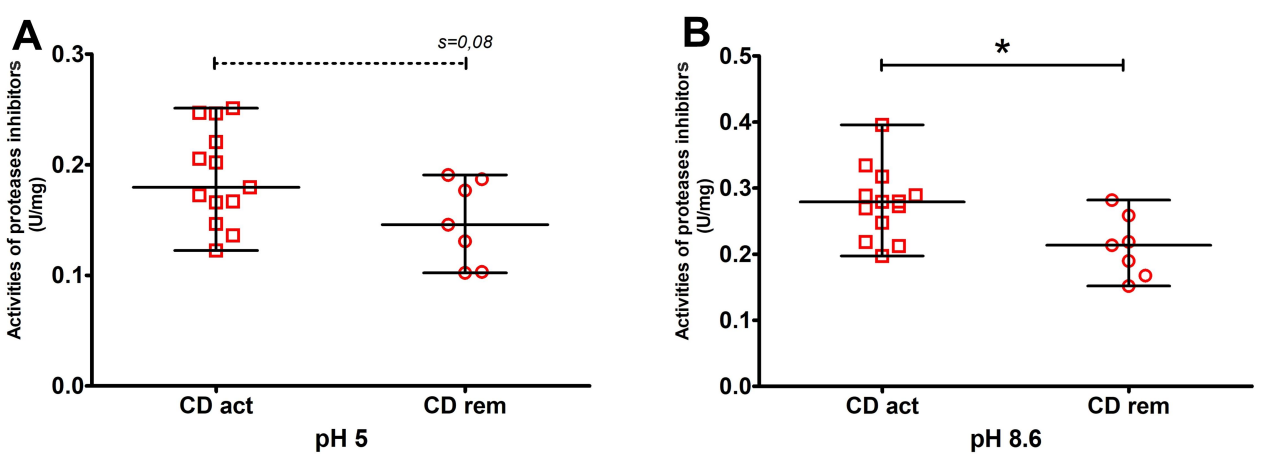

Figure 5 Activity of acidic $(\mathbf{A})(\mathrm{pH} 5.0 ; \mathrm{CD}$ act $\mathrm{N}=13, \mathrm{CD}$ rem $\mathrm{N}=7$ ) and alkaline (B) (8.6; $\mathrm{CD}$ act $\mathrm{N}=13, \mathrm{CD}$ rem $\mathrm{N}=7)$ protease inhibitors in the plasma of patients with Crohn's disease - active (act) and in remission ( $\mathrm{rem})$ (Median and range). The differences are statistically significant for comparisons between groups (act vs rem) at $* \mathrm{P} \leq 0.05$.

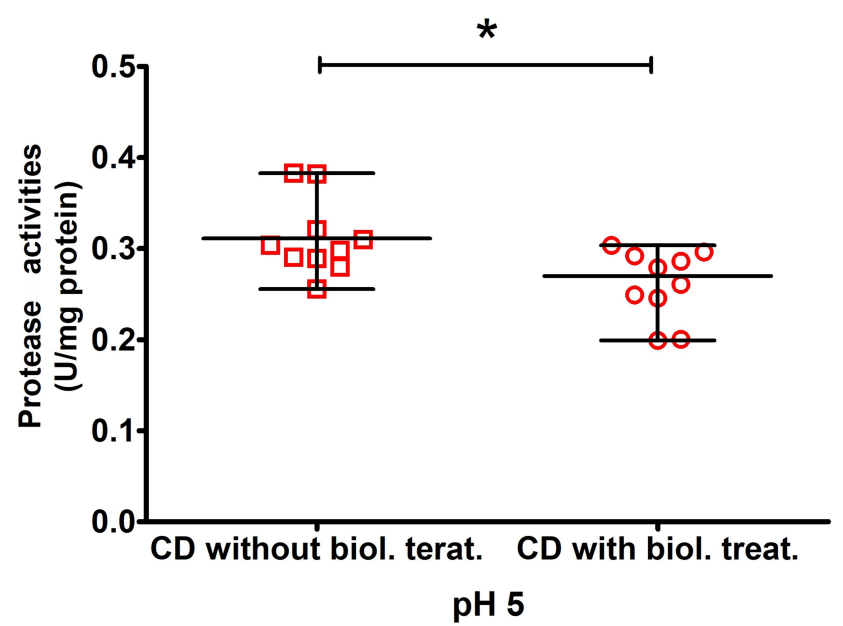

Figure 6 Activities of acidic proteases $(\mathrm{pH} 5.0)$ in patients with $(\mathrm{N}=10)$ and without biological treatment $(\mathrm{N}=10)$. The difference was statistically significant for comparisons between groups (with and without biological treatment) at $* \mathrm{P} \leq 0.05$. Other differences were statistically non-significant.

iodoacetamide, o-phenanthroline) were presented in the plasma of subjects in all groups.

\section{Discussion}

Excessive or poorly controlled inflammation is the central aspect of IBD. Host factors which regulate this inflammatory response play a crucial role in the pathophysiology of IBD. ${ }^{15}$ The activities of proteases must be strictly regulated to prevent inappropriate and often destructive proteolysis. Excessive and uncontrolled protease activities by endogenous inhibitors can lead to many disease states. ${ }^{16}$ Proteases associated with IBD exert proinflammatory effects: they potentiate the proinflammatory properties of cytokines and chemokines and remodel the extracellular matrix to enable leucocyte infiltration. Proteases degrade tight junction proteins, inducing plasma extravasation and increase intestinal permeability, and induce apoptosis in intestinal epithelial cells. ${ }^{4}$ Dysregulated proteolytic activity leads to homeostatic imbalance in the body. For this reason, a number of strategies have been developed to control proteolysis, including spatial and temporal regulation, zymogen activation, protease degradation, and inhibition of proteases by macromolecular inhibitors. ${ }^{16}$ Our research showed that plasma protease activities differed in patients with $\mathrm{CD}$ and $\mathrm{UC}$ as compared to the controls. Activities of acid ( $\mathrm{pH} \mathrm{5),} \mathrm{neutral}(\mathrm{pH} \mathrm{7)}$ and alkaline $(\mathrm{pH}$ 7.6; $\mathrm{pH}$ 8.6) proteases were lower in the group of $\mathrm{CD}$ patients than in the controls. The obtained results indicating a reduction in protease activities may be due to the effects of the treatment used in the group of patients. In the group of patients with $\mathrm{UC}$, the reduction in alkaline protease activities ( $\mathrm{pH} 8.6)$ was statistically significant compared to the control.

Several studies indicate an increase in proteases in inflammatory bowel disease. ${ }^{15}$ The statistically lower activities of proteases in our patients with IBD in comparison to the control group may be a response to treatment. Drugs used to treat IBD have been shown to have the capacity to induce apoptosis in $\mathrm{T}$ cells or monocytes in vitro and in vivo. ${ }^{17}$ Consequently, treatment and reduction of inflammation may have a decrease effect on the level of proteases in the study group of patients.

Evidence has shown that $\mathrm{T}$ helper type 1 (Th1)associated cytokines such as interferon (IFN)- $\gamma$ and TNF$\alpha$, as well as Th17-associated cytokines such as interleukin (IL)-17A and IL-23, play an important role in the pathogenesis of IBD. The disequilibrium between pro- and antiinflammatory cytokines and increased infiltration of activated immune cells such as T cells, B cells, natural killer cells, macrophages or neutrophils in the intestinal mucosa further aggravate mucosal inflammation in IBD. ${ }^{18}$ 

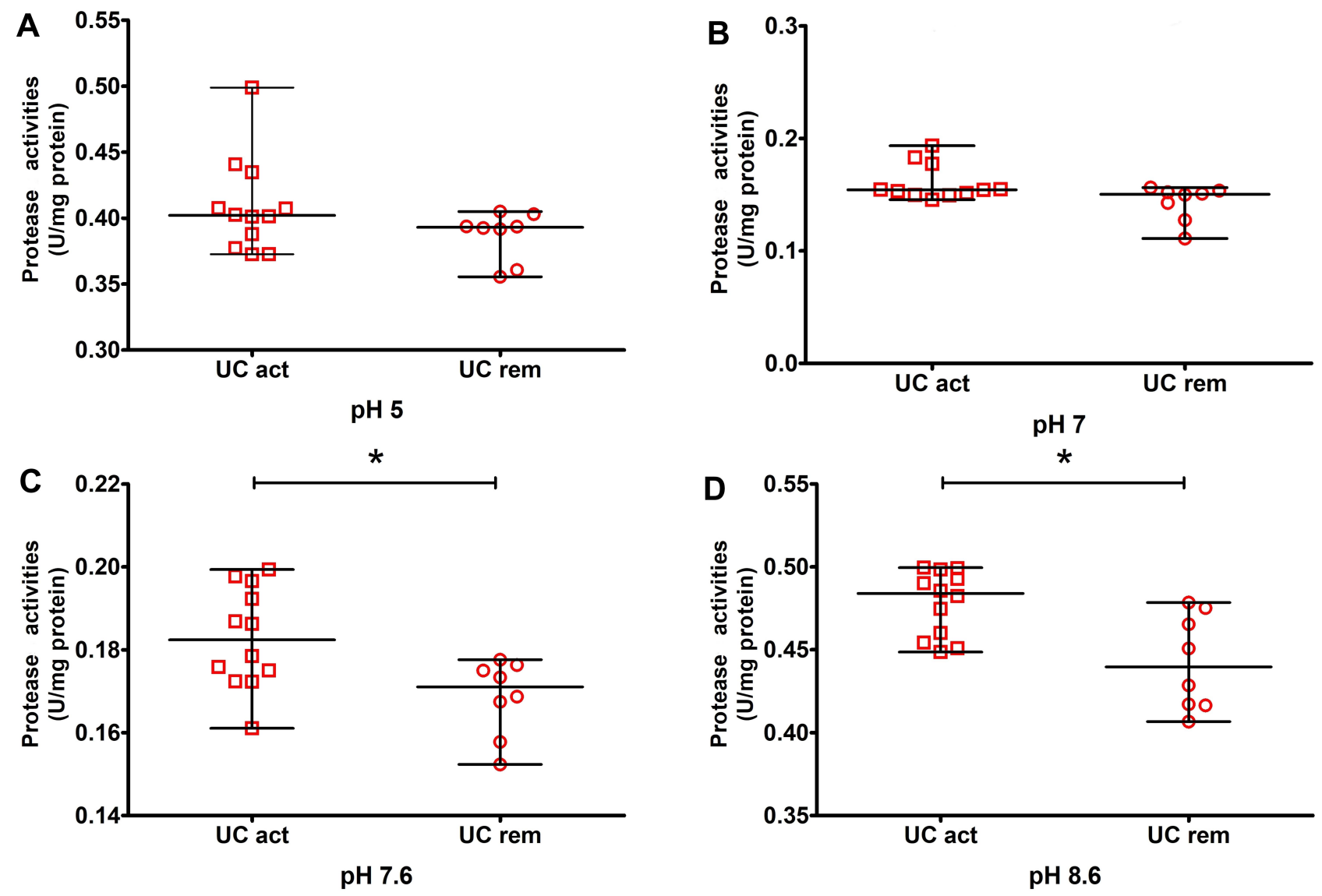

Figure 7 Activities of acidic (A) ( $\mathrm{pH}$ 5.0; $\cup C$ act $\mathrm{N}=12, \mathrm{UC}$ rem $\mathrm{N}=8$ ), neutral (B) ( $\mathrm{pH} 7.0 ; \mathrm{UC}$ act $\mathrm{N}=11, \mathrm{UC}$ rem $\mathrm{N}=8$ ) and alkaline (C and $\mathbf{D})(\mathrm{pH} 7.6$; $\cup C$ act $N=12, \mathrm{UC}$ rem $\mathrm{N}=8$ and 8.6; $\cup C$ act $N=12, U C$ rem N=8) proteases in the plasma of patients with $U C$ - active (act) and in remission (rem) (Median and range). The differences are statistically significant for comparisons between groups (act vs rem) at $* \mathrm{P} \leq 0.05$.
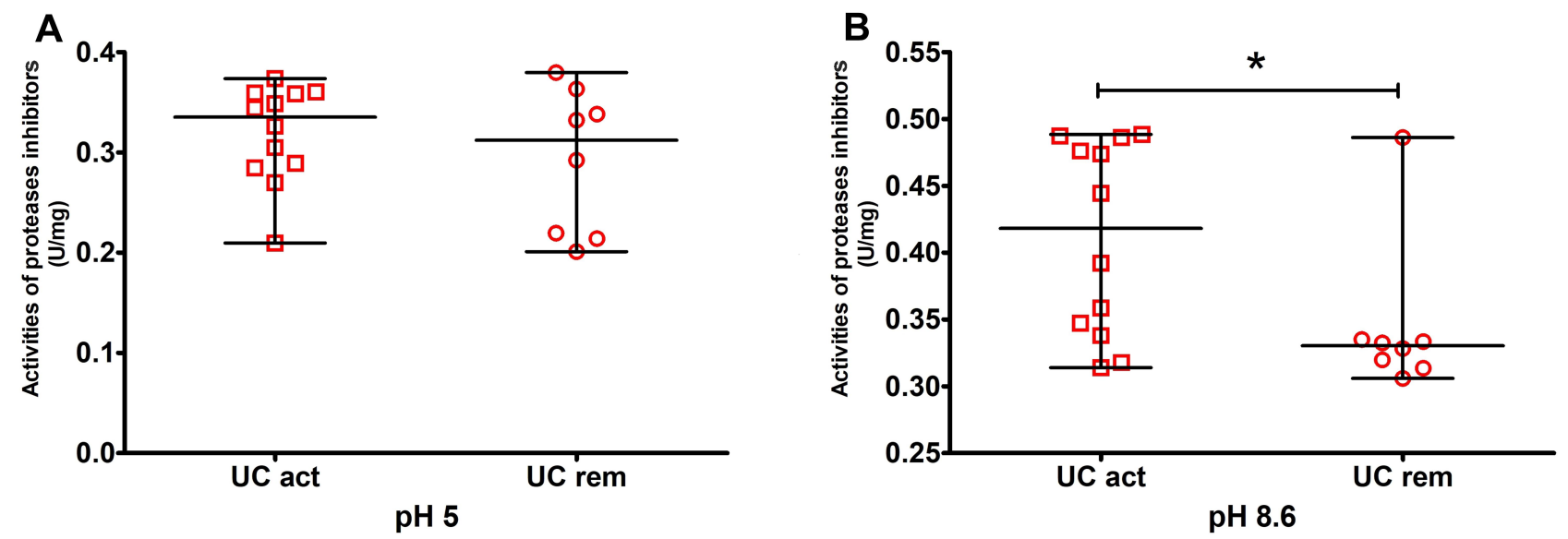

Figure 8 Activities of acid $(\mathbf{A})(\mathrm{pH} 5.0$; $\mathrm{UC}$ act $\mathrm{N}=12, \mathrm{UC}$ rem $\mathrm{N}=8$ ) and alkaline (B) (8.6; $\mathrm{UC}$ act $\mathrm{N}=12$, $\mathrm{UC}$ rem $\mathrm{N}=8)$ protease inhibitors in the plasma of patients with $\mathrm{UC}$ - active (act) and in remission (rem) (Median and range). The differences are statistically significant for comparisons between groups (act vs rem) at $* \mathrm{P} \leq 0.05$.

For this reason, we divided the patients in our study according to whether their disease was active or in remission, and the results were quite interesting. We observed a decrease in acid protease $(\mathrm{pH} \mathrm{5)}$ and alkaline protease
(pH 8.6) activities in the group of $\mathrm{CD}$ patients in remission in comparison with the active phase. Activities of alkaline (pH 7.6 and 8.6) proteases in the plasma of patients with ulcerative colitis in remission were also decreased in 
comparison to the active phase. Our research may suggest that the treatment used in IBD is to a large degree directed at reducing activated proteases.

Sulfasalazine is a drug considered a mainstay therapy for Crohn's disease or UC. It is composed of 5-ASA and a sulfapyridine moiety. Recent work indicates that sulfasalazine is a biologically active substance with potent antiinflammatory effects on intestinal epithelial cells or T lymphocytes. Sulfasalazine has been shown to interfere with the regulation of apoptosis by inhibiting the $\mathrm{NF} \kappa \mathrm{B}$ inflammatory pathway. In an experimental study, Doering et $\mathrm{al}^{19}$ showed that sulfasalazine had a potent proapoptotic effect on T lymphocytes in CD patients. ${ }^{19}$ This treatment, with potent anti-inflammatory effects and a proapoptotic effect on intestinal $\mathrm{T}$ cells, was used in our group of patients with IBD. In addition, azathioprine was used to treat the CD and UC patients.

The most commonly used agents in the management of IBD are azathioprine (AZA) and mercaptopurine (MP). AZA and MP induce apoptosis in activated lymphocytes. ${ }^{20}$ The thiopurine drugs, 6-mercaptopurine (6-MP) and its prodrug azathioprine (AZA) remain the mainstay of immunomodulatory therapy for IBD and are indicated in steroid-dependent and refractory patients as prophylaxis in CD. Their use is often limited because $30 \%$ to $50 \%$ of patients discontinue them due to side effects or lack of clinical efficacy. The lack of response to these immunomodulators has been attributed to differences in individual variations in drug metabolism. ${ }^{21}$

In the group of patients with CD treated biologically, acid protease activities ( $\mathrm{pH}$ 5.0) were lower than in Crohn's patients not receiving biological treatment.

The lower protease activities in patients with CD treated biologically, using Inflectra (infliximab) and Humira (adalimumab), may be the result of treatment directed at proinflammatory TNF- $\alpha$, which additionally contributed to the reduction in $\mathrm{CD}$ protease levels. A recent study has shown that increased matrix metalloproteinase activities in tissues from IBD patients was restored to control levels after infliximab treatment. ${ }^{4}$ Researchers have induced the production of matrix metalloproteinase-9 (MMP-9) by culturing cells at acidic $\mathrm{pH}(5.4-6.5) .^{22}$ Whereas Biancheri et $\mathrm{al}^{23}$ have shown that the proteolytic degradation may contribute to the nonresponsiveness of patients with IBD to anti-TNF agents. In the conducted studies, protease activity in plasma and mucosa were analysed. The research confirmed that the proteases MMP3 and MMP12, but not MMP9, cleave infliximab, adalimumab, and etanercept in vitro in a dose-dependent manner. Sera from IBD patients who did not respond to biologic therapy contained higher levels of MMP3-/MMP12-cleaved endogenous IgG and antihinge autoantibodies.

This is consistent with our observations, in which activity of acid proteases ( $\mathrm{pH}$ ) was significantly increased in the group of patients with active $\mathrm{CD}$ and in $\mathrm{CD}$ patients not receiving biological treatment, which may indicate increased MMP-9 activity in the patients. Increased MMP-9 activity may result in significant degradation of type IV collagen, the main component of the vascular basement membrane, a physical barrier preventing cells from migrating, thereby enabling leukocyte migration during inflammation. ${ }^{24}$ Biological therapy currently involves monoclonal antibodies directed against specific targets implicated in the pathogenesis of chronic inflammatory conditions. For IBD, this primarily encompasses approved anti-tumour necrosis factor (TNF) therapies (adalimumab, infliximab, golimumab or certolizumab), as well as agents, approved or under development, that target integrins (vedolizumab and natalizumab) or interleukin (IL)-12/23 (ustekinumab). ${ }^{25}$ The lack of significant differences in the activities of acid proteases $(\mathrm{pH} 5)$ in the UC groups in the active phase of the disease and in remission may be due to differences in the two diseases CD and UC. Despite some overlapping clinical features, these diseases are defined by separate inflammatory profiles and symptomatology and differ in gut microbiota composition. ${ }^{26}$ Microorganisms produce a vast array of aspartic, cysteine, metallo-, and serine proteases. However, it is not clear which commensal bacteria can secrete proteases that damage the mucosal barrier. ${ }^{27}$ Intestinal antimicrobial/microbial composition can influence treatment outcomes. ${ }^{28}$

Treatment choices for UC or CD also differ because they are entities with different pathophysiological aspects. ${ }^{29}$ One drug used to treat $\mathrm{CD}$, but not $\mathrm{UC}$, is methotrexate, which inhibits folic acid metabolism, required for many cell functions, including purine synthesis, and acts as a powerful inhibitor of cell metabolism and mitosis, ${ }^{28,30} \mathrm{CD}$ and UC also differ in their response to biological treatment. In CD, adalimumab is effective in the clinical setting and in patients with an attenuated response to infliximab, but it is less efficacious in UC. ${ }^{31}$

Our analyses showed significant lower activity of protease inhibitors in $\mathrm{CD}$ and $\mathrm{UC}$ patients in remission. This may be linked to the treatment used or decreased efficacy or expression of endogenous protease inhibitors, which can lead to upregulation of protease expression and the development of inflammation. Recent work has focused on the association of endogenous protease inhibitors with 
IBD pathology. ${ }^{32}$ During the disease process, the balance between proteases and their inhibitors is shifted, leading to altered spatial and temporal control of substrate cleavage. ${ }^{6}$

Intestinal tissues from $\mathrm{CD}$ and $\mathrm{UC}$ patients showed elevated proteolytic activity. This could be due either to upregulated protease expression or to decreased efficacy or expression of endogenous protease inhibitors. ${ }^{32}$ Our research may suggest that the immunomodulatory treatment used in IBD may affect the activity of proteases as well as their inhibitors by reducing inflammation and leukocyte levels.

One feature of the inflamed mucosa in IBD is the formation of cryptitis and abscesses, resulting from an influx of neutrophils into the epithelial area and intestinal lumen, and thus the accumulation of neutrophils, which is closely correlated with the activity of the disease, ${ }^{18}$ neutrophils releases large amounts of elastase, proteinase-3, and cathepsin G. Increased systemic and intestinal neutrophil activity has been found in inflamed UC mucosa, rather than in $\mathrm{CD}$, driving tissue damage (ulceration and crypt abscesses). ${ }^{33}$ These data have shown that neutrophil elastase balance can be important in colitis severity. Elastase is active in the $\mathrm{pH}$ range from 7 to 9 . In our research activities of alkaline ( $\mathrm{pH} 7.6$ and 8.6) proteases in the plasma of patients with ulcerative colitis in remission were decreased in comparison to the active phase.

Our study showed that protease activities in $\mathrm{CD}$ and UC patients were significantly lower in the remission stage, which involves a reduction in the inflammatory state and a reduced influx of neutrophils into the epithelial area. This may suggest that the reduction in proteases in the $\mathrm{CD}$ and UC group may also be associated with the reduction in inflammatory markers in response to treatment.

\section{Conclusions}

1. Our research may suggest that the immunomodulatory treatment used in IBD, aimed at reducing leukocyte levels and reduction of inflammation may contribute to a reduction in protease activity.

2. The decrease in the levels of proteases in patients with $\mathrm{CD}$ and $\mathrm{UC}$ in remission may be a marker of the patients' response to the treatment.

\section{Data Sharing Statement}

The datasets used/or analyzed during the current study are included in this published article.

\section{Ethical Approval and Consent to Participate}

All patients were recruited following written informed consent, the protocol was approved by the Local Bioethics Committee in Lublin KE-0254/180/2016. The consent of the Bioethics Committee was issued until 2021. The study protocol conforms to the ethical guidelines of the 1975 Declaration of Helsinki as reflected in a priori approval by the institution's human research committee.

\section{Author Contributions}

All authors contributed to data analysis, drafting or revising the article, have agreed on the journal to which the article will be submitted, gave final approval of the version to be published, and agree to be accountable for all aspects of the work.

\section{Disclosure}

The authors declare that they have no conflicts of interest for this work.

\section{References}

1. Dudzińska E, Szymona K, Gil-Kulik P, et al. Imbalance of controlled death in peripheral blood lymphocytes in Crohn's disease and ulcerative colitis. Medicina. 2019;55(6):231. doi:10.3390/medicina55060231

2. Dubois-Camacho K, Ottum PA, Franco-Muñoz D, et al. Glucocorticosteroid therapy in inflammatory bowel diseases: from clinical practice to molecular biology. World $J$ Gastroenterol. 2017;23(36):6628-6638. doi:10.3748/wjg.v23.i36.6628

3. Antalis TM, Shea-Donohue T, Vogel SN, et al. Mechanisms of disease: protease functions in intestinal mucosal pathobiology. Nat Clin Pract Gastroenterol Hepatol. 2007;4(7):393-402. doi:10.1038/ ncpgasthep 0846

4. Herszényi L, Barabás L, Hritz I, et al. Impact of proteolytic enzymes in colorectal cancer development and progression. World j Gastroenterol. 2014;20(37):13246-13257. doi:10.3748/wjg.v20. i37.13246

5. Denadai-Souza A, Bonnart C, Tapias NS, et al. Functional proteomic profiling of secreted serine proteases in health and inflammatory bowel disease. Sci Rep. 2018;8(1):7834. doi:10.1038/s41598-01826282-y

6. Edgington-Mitchell LE. Pathophysiological roles of proteases in gastrointestinal disease. Am J Physiol Gastrointest Liver Physiol. 2016;310(4):G234-9. doi:10.1152/ajpgi.00393.2015.

7. Steck N, Mueller K, Schemann M, et al. Bacterial proteases in IBD and IBS. Gut. 2012;61(11):1610-1618. doi:10.1136/gutjnl-2011300775

8. Schacterle GR, Pollack RL. A simplified method for the quantitative assay of small amounts of protein in biologic material. Anal Biochem. 1973;51(2):654-655. doi:10.1016/0003-2697(73)90523-X

9. Łoś A, Strachecka A. Fast and cost-effective biochemical spectrophotometric analysis of solution of insect "blood" and body surface elution. Sensors. 2018;18(5):1494. doi:10.3390/s18051494

10. Anson M. The estimation of pepsin, trypsin, papain and cathepsin with hemoglobin. J Gen Physiol. 1938;22:79-84. doi:10.1085/ jgp.22.1.79 
11. Grzywnowicz K, Ciołek A, Tabor A, et al. Profiles of the body-surface proteolytic system of honey bee queens, workers and drones: ontogenetic and seasonal changes in proteases and their natural inhibitors. Apidologie. 2009;40:4-19. doi:10.1051/apido:2008057

12. Strachecka A, Gryzińska M, Krauze M. The influence of environmental pollution on the protective proteolytic barrier of the honey bee Apis mellifera mellifera. Polish J Environmental Studies. 2010;19 (4):855-859.

13. Strachecka A, Gryzińska M, Krauze M, et al. Profile of the body surface proteolytic system in Apis mellifera queens. Czech J Anim Sci. 2011;56:15-22. doi:10.17221/150/2009-CJAS

14. Lee T, Lin Y. Trypsin inhibitor and trypsin-like protease activity in air- or submergence-grown rice (Oryza sativa L.). Coleoptiles Plant Sci. 1995;106:43-54. doi:10.1016/0168-9452(95)04058-3

15. Saeed MA, Ng GZ, Däbritz J, et al. Protease-activated receptor 1 plays a proinflammatory role in colitis by promoting th17-related immunity. Inflamm Bowel Dis. 2017;23(4):593-602. doi:10.1097/ MIB.0000000000001045

16. Farady CJ, Craik CS. Mechanisms of macromolecular protease inhibitors. Chembiochem. 2010;11(17):2341-2346.

17. Lügering A, Lebiedz $\mathrm{P}$, Koch S, et al. Apoptosis as a therapeutic tool in IBD? Ann N Y Acad Sci. 2006;1072:62-77. doi:10.1196/ annals. 1326.013

18. Zhou GX, Liu ZJ. Potential roles of neutrophils in regulating intestinal mucosal inflammation of inflammatory bowel disease. J Dig Dis. 2017;18(9):495-503. doi:10.1111/1751-2980.12540

19. Doering J, et al. Induction of T lymphocyte apoptosis by sulphasalazine in patients with Crohn's disease. Gut. 2004;53(11):1632-1638. doi:10.1136/gut.2003.037911

20. Stocco G, Pelin M, Franca R, et al. Pharmacogenetics of azathioprine in inflammatory bowel disease: a role for glutathione-S-transferase? World J Gastroenterol. 2014;20(13):3534-3541. doi:10.3748/wjg. v20.i13.3534

21. Bradford K, Shih DQ. Optimizing 6-mercaptopurine and azathioprine therapy in the management of inflammatory bowel disease. World $J$ Gastroenterol. 2011;17(37):4166-4173. doi:10.3748/wjg.v17. i37.4166

22. Kato Y, Lambert CA, Colige AC, et al. Acidic extracellular pH induces matrix metalloproteinase-9 expression in mouse metastatic melanoma cells through the phospholipase D-mitogen-activated protein kinase signaling. J Biol Chem. 2005;280(12):10938-10944. doi:10.1074/jbc.M411313200
23. Biancheri P, Brezski RJ, Di Sabatino A. Proteolytic cleavage and loss of function of biologic agents that neutralize tumor necrosis factor in the mucosa of patients with inflammatory bowel disease. Gastroenterology. 2015;149(6):1564-1574.e3. doi:10.1053/j. gastro.2015.07.002.

24. Lipka D, Boratyński J. Metalloproteinases. Structure and function. Postepy Hig Med Dosw. 2008;62:328-336 e.

25. Moss AC. Optimizing the use of biological therapy in patients with inflammatory bowel disease. Gastroenterol Rep. 2015;3(1):63-68. doi:10.1093/gastro/gou087.

26. Dudzińska E, Gryzinska M, Kocki J. Single nucleotide polymorphisms in selected genes in inflammatory bowel disease. Biomed Res Int. 2018;2018:6914346. doi:10.1155/2018/6914346

27. Carroll IM, Maharshak N. Enteric bacterial proteases in inflammatory bowel disease- pathophysiology and clinical implications. World $J$ Gastroenterol. 2013;19(43):7531-7543. doi:10.3748/wjg.v19. i43.7531

28. Magnusson MK, Strid H, Sapnara M, et al. Anti-TNF therapy response in patients with ulcerative colitis is associated with colonic antimicrobial peptide expression and microbiota composition. J Crohns Colitis. 2016;10(8):943-952. doi:10.1093/ecco-jcc/jjw051

29. Sales-Campos H, Basso PJ, Alves VB, et al. Classical and recent advances in the treatment of inflammatory bowel diseases. Brazilian j Med Biol Res. 2014;48(2):96-107. doi:10.1590/1414$431 \times 20143774$

30. Mulder DJ, Noble AJ, Justinich CJ, et al. Tale of two diseases: the history of inflammatory bowel disease. J Crohns Colitis. 2014;8 (5):341-348. doi:10.1016/j.crohns.2013.09.009

31. Trinder MW, Lawrance IC. Efficacy of adalimumab for the management of inflammatory bowel disease in the clinical setting. J Gastroenterol Hepatol. 2009;24(7):1252-1257. doi:10.1111/ j.1440-1746.2009.05786.x.

32. Bermúdez-Humarán LG, Motta JP, Aubry C, et al. Serine protease inhibitors protect better than IL-10 and TGF- $\beta$ anti-inflammatory cytokines against mouse colitis when delivered by recombinant lactococci. Microb Cell Fact. 2015;14:26. doi:10.1186/s12934-0150198-4

33. Curciarello R, Sobande T, Jones S, et al. Human neutrophil elastase proteolytic activity in ulcerative colitis favors the loss of function of therapeutic monoclonal antibodies. J Inflamm Res. 2020;13:233-243. doi: $10.2147 /$ JIR.S234710
International Journal of General Medicine

\section{Publish your work in this journal}

The International Journal of General Medicine is an international, peer-reviewed open-access journal that focuses on general and internal medicine, pathogenesis, epidemiology, diagnosis, monitoring and treatment protocols. The journal is characterized by the rapid reporting of reviews, original research and clinical studies across all disease areas. The manuscript management system is completely online and includes a very quick and fair peer-review system, which is all easy to use. Visit http://www.dovepress.com/ testimonials.php to read real quotes from published authors. 